\title{
EL IMPACTO DEL HUMANISMO RENACENTISTA EN LA CONCEPCIÓN DE LA LÓGICA
}

Pilar CAstril lo Criado Dpto. de Lógica. UNED

\section{Introducción}

Una de las disciplinas más vigorosamente afectadas por el impacto del humanismo fue sin duda la de la logica. Su valor, sin embargo, ha sido puesto en entredicho por la mayor parte de los historiadores de la lógica para quienes el humanismo fue, si no el principal, sí uno de los factores desencadenantes del declive en el que esta disciplina entró desde entonces y del que ya no se recuperaría hasta mediados del siglo XIX. Sin embargo, dada la falta de estudios pormenorizados sobre las aportaciones de esta tradición de la dialéctica humanista en temas concretos como el de la argumentación no-deductiva o el de la teoría de los tópicos, esta apreciación no deja de pecar de infundada o cuando menos de un tanto precipitada. Los estudios pioneros en este campo, con su descripción de los contomos del mismo y su caracterización de textos hasta entonces desconocidos, sirvieron ya para poner de manifiesto que el de la dialéctica humanista fue un movimiento con una vitalidad y grado de incidencia en el pensamiento posterior mucho mayores de los que hasta entonces se había pensado. ${ }^{1}$ La reciente recuperación de buena parte de estos textos, de muchos de los cuales disponemos ahora de reimpresiones

\footnotetext{
${ }^{1}$ Me refiero especialmente a W.S. Howell, Logik and Rhetorik in England, 1500-1700, Princeton, 1956; W. Risse, Die Logik der Neuzeit, Band I, Stuttgart, 1964, y C. Vasoli, La dialettica e la retorica dell'Umanesimo, Milán, 1968.

Endoxa: Series Filosóficas, $n^{\circ}$ 5, 1995, UNED, Madrid:

Pilar Castrillo Criado: El impacto del Humanismo Renacentista en la concepción de la lógica.

pp. $91-114$.
} 
y en algunos casos hasta de ediciones críticas, hace que sea el momento oportuno para replantearse la cuestion de si el humanismo, con su exacerbada preocupación por las cuestiones de forma y estilo, fue un movimiento de carácter exclusivamente retórico-literario y que, en consecuencia, puede ser alegremente pasado por alto por el historiador de las ideas lógicas o si, por el contrario, la dialéctica que dentro de esta tradición llegó a pergeñarse pudiera tener acaso alguna relación directa $o$ indirecta con el estudio de la inferencia.

Entre los rasgos que caracterizan al movimiento humanista, uno de los más destacados lo constituye la nueva actitud adoptada respecto de la lógica y del papel que tal disciplina había de desempeñar en los programas de enseñanza de las artes liberales. No es que los humanistas pensaran que la lógica había de tener en dichos programas menos relevancia de la que los escolásticos le habían conferido (de hecho, la lógica ocupó en ellos el mismo lugar primordial), sino que lo que ocurrio fue que se produjo un cambio de actitud respecto al modo de concebir el proceso educativo y, como consecuencia, respecto a la idea de la función que esta disciplina había de desempeñar en dicho proceso. Fue su convicción de que la educación había de tener una función utilitaria como medio de preparación para la vida cívica lo que llevó a los humanistas primero a rechazar, y luego a reemplazar, la logica escolástica tal y como ésta les había sido legada. Ésta no era otra que la llamada lógica moderna, esto es, el complejo sistema lógico-semántico forjado a mediados del sigo XIII por lógicos como W. de Sherwood, L. de Auxerre, y sobre todo Petrus Hispanus, cuyas Summulae logicales hicieron las veces de libro de texto en las principales universidades europeas por lo menos hasta mediados del siglo XVI. Este sistema incluía, además de las tradicionales logica vetus y lógica nova, una amplia exposición de las distintas técnicas linguísticas que en la edad media se habían ido forjando con ánimo de poder abordar temas como los de la denotación y la connotación de los términos y que se hallaban recogidas en los llamados Parva logicalia.

Lo que de esta lógica escolástica tardía va a resultarles más inaceptable a los reformadores humanistas es su falta de operatividad. No 
es que estas investigaciones estén exentas a sus ojos de otros problemas, toda vez que también las tachan de excesivamente técnicas, abstractas y abstrusas. Pero va a ser su carácter no-operativo lo que concite la mayor parte de las críticas humanistas, hasta el punto de que puede decirse que este tema, junto con el de la invitación a liberarse de la autoridad de Aristóteles, constituye uno de los tópicos más recurrentes de todo el pensamiento humanista, desde Petrarca hasta $P$. Ramus, pasando por $L$. Valla, L. Vives o M. Nizolio.

Las razones por las que los lógicos humanistas enfatizaron tanto las virtudes prácticas de la lógica habría que buscarlas en la creciente importancia que los debates y las disputas habían llegado a adquirir en los distintos ámbitos de la vida ć́vica. Esta situación demandaba una lógica capaz de proveer de argumentos convincentes y persuasivos, demanda a la que la lógica escolástica, con su atención centrada exclusivamente en las formas válidas de razonar, era incapaz de dar satisfacción. Fue fundamentalmente esta incapacidad de la vieja logica lo que indujo a los humanistas a reformarla y a introducir un cambio radical en su foco de interés, foco que se vió desplazado del estudio del silogismo al de la invención y disposición de tópicos para hallar argumentos susceptibles de ser empleados en las disputas. Una primera consecuencia práctica que tuvo este desplazamiento fue que con él desapareció la línea de demarcación aristotélico-escolástica entre el estudio de la argumentación válida a partir de premisas ciertas (lo que Aristóteles había denominado lógica apodíctica) y el de la argumentación que parte de premisas plausibles (lo que había denominado dialéctica). Esta desaparición llevó a los humanistas a identificar la dialéctica --lo que en la época se conocía por el nombre de ars disserendi- con el todo de la lógica, entendiendo por tal ahora ya no el estudio de la argumentación válida, sino el estudio de la argumentación tout court, i.e, no sólo del argumento cierto, sino también del probable y el sofístico. ${ }^{2}$ No conviene

\footnotetext{
${ }^{2}$ El uso del termino 'dialéctica' para referirse a la totalidad de la lógica se remonta a autores como Cicerón o Martianus Capella, predominando sobre el de 'lógica' durante los primeros tiempos de la edad media. (vide E.J.Ashworth, Language and Logic in the postmedieval period, Dorcrecht, Reidel Pub. Co., 1974, p. 22). El término fue introducido por Aristóteles para designar el estudio de los tópicos o de los argumentos probables. en tanto
} 
olvidar que el interés primordial de los humanistas radicaba en los problemas de oratoria y exégesis textual, y que es precisamente su concepción de la lógica como un medio para el análisis y comprensión de los textos canónicos de las autoridades de la antiguiedad y como una ayuda para la composición de discursos emulativos de los de aquéllos lo que les llevará a fijarse el cometido de dar cuenta, en su tratamiento de la argumentación, no sólo de los patrones válidos de razonar, sino también, y de manera preferente, de estrategias argumentativas no válidas, pero eficaces en el debate y la discusión. En otras palabras, frente a la preocupación exclusiva de los escolásticos por los patrones válidos de argumentar, los dialécticos humanistas van a caracterizarse por prestar una mayor atención a la dimensión pragmática de la argumentación que a los aspectos formales de la misma, siendo ésta sin duda una de las principales señas de identidad de este movimiento.

Como era de esperar, el juicio que a quienes hasta ahora han pergeñado la historia de la lógica les ha merecido este cambio de énfasis introducido por los humanistas no podría ser más negativo. Así, William y Martha Kneale no dudan en considerarlos los auténticos culpables de la corrupción y el declive a que llevaron a nuestra disciplina, en tanto que seguidores de Cicerón y Quintiliano, autores éstos de los que

heredaron los hombres del Renacimiento su actitud romana ante el mundo de la cultura, con el resultado de que la auténtica lógica se viera desplazada por la retórica y de que Cicerón fuese citado en los libros supuestamente dedicados a nuestra disciplina con tanta asiduidad como Aristóteles. Lorenzo Valla, que denunció la falsa donación de Constantino, y Rudolph Agrippa [sic] fueron dos de los escritores con los que comenzó el proceso de corrupción de la logica. $^{3}$

que contrapuestos a los demostrativos y a los sofísticos.

${ }^{3}$ Cf. El desarrollo de la lógica (Madrid, Tecnos, 1972), p. 278. Repárese en que los autores confunden al humanista y autor de un importante texto de dialéctica Rudolph Agricola con Henricus Comelius Ágrippa, médico, astrólogo y autor del influyente tratado sobre magia, De occulta philosophia. 
Semejante apreciación, que por lo demás tiene el inconveniente de no tomar en consideración el hecho de que el estancamiento en los estudios lógicos no siguió sino que precedió a la consolidación de los studia humanitatis, es probable que no fuera compartida por quienes dedican sus esfuerzos a un nuevo campo de estudio que desde hace algunos años lucha por hacerse con un hueco en la Academia y cuyos presupuestos presentan muchos puntos en común con la tradición humanista y su modo de entender la lógica. Me refiero naturalmente a la llamada 'teoría de la argumentación' o 'teoría crítica', caracterizada precisamente por proclamar la necesidad de prestar una mayor atención al estudio de la argumentación en el lenguaje natural y por defender la idea de que la lógica debe de ser 'naturalizada', entendiendo por tal no ya que la lógica debe tomar por objeto de estudio la inferencia real, y no la mera implicación, sino incluso, al menos en algunos casos, que la lógica debe ser natural, tanto en lo que se refiere a su enfoque, como en lo que atañe a su propósito.

\section{El combate contra la 'barbarie' escolástica}

Para poder llegar a una valoración más ecuánime de la dialéctica humanista, una de las cosas que es preciso empezar por hacer es tratar de aclarar el significado que tuvo la polémica de los primeros humanistas contra los escolásticos, pues si alguna causa aglutinó a los pioneros de este movimiento, ésta fue sin duda la de la descalificación y crítica del discurso filosofico y lógico de los escolásticos, a quienes no dudaron en tachar de 'bárbaros' en sus escritos. En esta descalificación van a converger, sin embargo, figuras un tanto distintas y distantes en el tiempo, cosa que conviene tener presente para no pasar por alto los matices diferenciales que pudieran encerrarse en las distintas críticas que se sitúan en la línea que va de la 'edad de las tinieblas' de Petrarca a la 'corrupción de las artes' de Luis Vives, pasando por los 'bárbaros' de Leonardo Bruni o de Lorenzo Valla. En un principio esta crítica se configura como contraposición entre los 'antiguos' --los clásicos grecorromanos que constituyen el modelo a imitar-- y los 'modernos' -- 
lógicos, físicos y teólogos, profesores de las universidades inglesas y francesas principalmente-- si bien lo que con tales epítetos quiere darse a entender variará también ligeramente de un autor a otro. ${ }^{4}$

Conviene destacar, sin embargo, que estas acusaciones de falta de elegancia y claridad que los humanistas hacen al discurso escolástico no son nunca, cualesquiera que puedan ser sus diferencias, acusaciones puramente formales. En la polémica entre los humanistas y los escolásticos no se ventilaba únicamente una pura cuestión de forma y estilo, sino que desde sus inicios queda claro ya que lo que estaba en juego en ella era la idea que unos y otros tenían de la naturaleza y objetivos de lalógica. Así, cuando Petrarca insiste en que el fin de la educación no es otro que la familiarización con las obras de la antigüedad clásica y que gramática, retórica y dialéctica han de tomarse no como fines en sí mismos, sino como propedeúticas necesarias para el conocimiento, está en realidad polemizando contra los intentos reduccionistas de la dialéctica escolástica y contra su inutilidad, i.e., está contraponiendo una concepción de la lógica a otra. ${ }^{5}$ Y lo mismo ocurre con la durísima descalificación a que Leonardo Bruni somete a los lógicos británicos -cabeza de turco desde entonces de la crítica humanística- en su Ad Petrum Paulum Histrum Dialogus, diálogo dirigido a Pedro Pablo Vergerio, autor de uno de los primeros tratados humanistas sobre educación, y en el que el

\footnotetext{
${ }^{4}$ El contraste entre edad de las tinieblas y Renacimiento alimentará una polémica de casi cuatro siglos de duración desde sus inicios en el siglo XIV, pero que, como es obvio, irá adquiriendo significados y tonos muy distintos durante todo este tiempo. Sobre este conflicto entre 'antiguos' y 'modernos', a propósito del tema de la dialéctica. Cf. el trabajo de E. Garin, "La cultura fiorentina nella seconda metà del Trecento e i 'barbari britanni'", recogido en E. Garin L'età nuova. Ricerche di storia della cultura dal XII al XVI secolo, Morano, Nápoles, 1969, pp.141-166 y el de C. Vasoli, "Intomo al Petrarca e ai logici 'moderni'", en Miscellanea Mediaevalia... 9: Antiqui und Moderni. Traditionsbewusstsein und Tortschrittbewusstsein im Späten Mittelalter, Walter de Gruyter, Berlín, 1974, pp. 142154.

5 Petrarca Le familiari, I.2, citado en L. Jardine, "Humanistic Logic", The Cambridge History of Renaissance Philosophy, ed. C. Schmit et al., (Cambridge Univ. Press, 1988) p. 176: 'Respice et hos qui in altercations et cavillationibus dyalecticistotum vite tempus expendunt seque inanibus semper questiunculis exagitant; et presagium meum de omnibus habeto: omnium nempe cum ipsis fama corruet unumque sepulchrum ossibus sufficiet ac nomini. Cum enim mors frigidam linguam stare coegerit, non modo ut sileant necesse est, sed ut de his etiam sileatur'. Sobre la actitud de Petrarca ante la dialéctica escolástica, véase C. Vasoli op. cit.,en la nota 1, pp. 9-15.
} 
canciller florentino confiesa que de estos autores le atemorizan hasta sus nombres, "que parecen sacados de las cohortes de Radamanto".

No faltan desde luego humanistas que parecen preocupados casi exclusivamente por las cuestiones de estilo, como es, por ejemplo, el caso del famoso erudito veneciano Ermolao Barbaro, a juzgar por la postura que adoptó en la célebre polémica mantenida con el no menos célebre Pico della Mirandola a propósito de la escolástica. ${ }^{7}$ Pero incluso éstos, cuando acusan a los escolásticos de 'bárbaros', están queriendo significar algo más que el mero hecho de que la belleza y corrección de estilo están por completo ausentes de sus construcciones. Como ha escrito acertadamente E. Garin, "Es cierto que durante siglo y medio circulará ampliamente la opinión de que los bárbaros escolásticos escribían mal y traducían peor. No obstante, la tosquedad de su estilo no es subrayada por la necesidad de elegancas formales; o dicho de otro modo, la antítesis entre forma 'bárbara' y forma elegante se plantea desde un ángulo no meramente formalista: un discurso 'bárbaro' es un discurso inhumano e irreal, un cálculo o una fórmula sin validez, lo mismo que una traducción bárbara constituye una traducción infiel, sin significado, que nada traduce" $^{8}$

El tema de la corrupción del latín a manos de los cultivadores escolásticos de la lógica y de la falta de elegancia y erudición de sus escritos no alimentó la polémica únicamente en Italia, sino que no tardó en pasar de los humanistas italianos a sus correligionarios del norte. Lo

\footnotetext{
${ }^{6}$ E.Garin, Prosatori latini, 1952, pp. 58 y ss.: "Quid autem de dialectica, quae una ars ad disputandum pernecessaria est? An ea florens regnum obtinet, neque hoc ignorantia bello calamitatem ulam perpessa est? Minime vero. Nam etiam illa barbaria, quae trans oceanum habitat, in illam impetum fecit. At quae gentes, dii boni? Quorum etiam nomina perhorresco: Farabrich, Buser, Occam, alique eiusmodi, qui omnes mihi videntur Rhadamantis cohorte traxisse cognomina."

${ }^{7}$ Para las cartas de Pico della Mirandola y la respuesta de Ermolao Barbaro, Cf. E. Garin, Prosatori latini, pp. 804-823. La versión inglesa de estas cartas puede verse en $Q$. Breen, "Giovanni Pico della Mirandola on the conflict of Philosophy and Rhetoric", Journal of the History of Ideas XIII (1952):384-426, que incluye tambiên la carta que, en defensa de la postura de Barbaro y en contra de la de Pico, escribe Melanchthon, unos cuantos años después de fallecidos ambos.

${ }^{8}$ E. Garin, "Los humanistas y la ciencia", en La revolución cultural del Renacimiento, Crítica, Barcelona, 1984, p. 255.
} 
hallamos presente, entre otros, en Tomas Moro, Rodolfo Agricola y Petrus Ramus, e incluso alcanzamos a oir sus ecos en pensadores que se hallan a caballo entre el Renacimiento y la modemidad, como es el caso de Francis Bacon. Pero si hay un autor que haya sintetizado de manera completa todos los argumentos esgrimidos por los humanistas en su crítica de la escolástica, éste es sin lugar a dudas el valenciano Juan Luis Vives. Alumno en su juventud del colegio Montaigu de la Universisdad de Paris y familiarizado por tanto con la lógica escolástica que habra aprendido a través del estudio de los tratados nominalistas entonces en boga en el Estudio General de dicha ciudad, ${ }^{9}$ el desencanto que ésta le produce le lleva a escribir una dura invectiva contra ella de la que muchos de los autores posteriores extraerán sus temas y argumentos. El propósito de esta invectiva, que ve la luz en 1519 bajo el título de In Pseudodialecticos, no es sino el de incitar a los no pocos españoles que entonces pululaban por la universidad de París a dar la espalda a la escolástica y a entrar en los nuevos tiempos, i.e., a abrazar la causa del humanismo que él ya había hecho suya tras sus contactos con Nicolás Bérault y sobre todo con Guillermo Budé. ${ }^{10}$

Movido por el propósito de restablecer la dialéctica sobre la firme base del usus commnis loquendi, la primera cosa de la que, siguiendo a sus antecesores, acusa Vives a los escolásticos en esta crítica es de haber corrompido la lengua latina, tanto en su vocabulario como en su sintaxis. El uso que los autores escolásticos hacen del latín --alega-- se aparta tanto del usual que "no son entendidos no ya por los más duchos en esa lengua, sino a veces ni tan siquiera por quienes son de la misma harina

${ }^{9}$ Es precisamente en este colegio Montaigu, en el que Vives fue alumno de Gaspar Lax de Sariñena y de Juan Dullaert de Gante, en donde se produce un resurgimiento del nominalismo y de la filosofía terminista. Rita Guerlac, en su Jean Luis Vives against the Pseudodialecticos (Dordrecht, Reidel, 1979), pp. 19-24, ofrece una panorámica de las principales figuras que conformaron este movimiento.

10 La reputación que este grupo de españoles tenía era la de ser, junto con los escoceses, los más reacios a adaptarse a los nuevos tiempos. Vives elige para su diatriba la forma de carta a un amigo, el aragonés Juan Fort, y en la dedicatoria que la encabeza da cuenta de la necesidad que siente de manifestar su repulsa hacia el sistema docente de la universidad de París, en donde una serie de hombres se han empeñado en abrazar 'una fea barbarie' en lugar de dedicarse al cultivo del verdadero saber. Cf. In Pseudodialecticos. A critical edition, ed. C. Fantazzi, Leiden, E. J. Brill, 1979, pp. 27-29. 
o, por mejor decir, del mismo salvado (hominem eiusdem furfuris)"." La causa de ello no es otra, para él, que el hecho de que dichos autores no acuden en busca de guía a quienes procedería, sino a Pedro Hispano, del que Vives hace verdadero chivo expiatorio en esta obra: "Pero este sentido [el verdadero de las oraciones latinas] ¿a qué autores van a pedirlo estos majaderos?", se pregunta, para luego responder: " No a Cicerón, no a Quintiliano, tampoco a Boecio, hombres de auténtica latinidad que en cuestiones de latín merecen un crédito absoluto, sino a Pedro Hispano". ${ }^{12}$ "Pobre Cicerón!, ¡Pobre Quintiliano!, ¡Pobre Boecio!", concluye con ironía, "iSi Pedro Hispano conoció mejor que todos ellos la fuerza de la lengua latina!". ${ }^{13}$

Conviene reparar en que lo que en el fondo subyace a esta postura en contra de la artificiosidad y complejidad del lenguaje lógico forjado por los escolásticos es la convicción, que tan perniciosas consecuencias para el desarrollo inmediato de nuestra disciplina había de tener, de que el estudio de la lógica ha de ser regulativamente descriptivo más bien que prescriptivo. Esta idea que, como enseguida veremos, ya había sido mantenida por Valla con absoluta claridad, es defendida de modo inequívoco por el insisgne valenciano al afirmar : "no hablamos de cierto modo el latín porque la gramática latina así lo preceptúe, sino que antes al contrario, la gramática nos recomienda que hablemos así porque es el

${ }^{11}$ In Pseudodialecticos, ed: de C. Fantazzi, p.35: "At isti non dico non intelliguntur doctissimis latine, cum se latini dicant loqui, sed interdum ne ab hominis quidam eiusdem farinae, seu eiusdem potius furfuris". Aunque los humanistas tienen un vocabulario y modo de expresión bastante comunes, abundan en In Pseudodialecticos expresiones (como ésta de hombres ' eiusdem furfuris') que Tomás Moro había empleado en una carta a Martin Dorp de 1515. Así se lo deja entrever Moro a Erasmo cuando no sin cierta ironía le confiesa: "Lo que ha escrito [Vives] contra los pseudodialécticos me produce un peculiar placer. Ello es debido no sólo a que ridiculiza las estúpidas sutilezas con ingenosas chanzas, se opone a ellas con argumentos válidos y las derriba y destruye con un razonamiento irrefutable, sino también a que veo allí ciertos asuntos tratados casi con los mismos argumentos que yo esgrimi cuando todavía no había leido a Vives". Carta de Moro a Erasmo, recogida en R. Guerlac, Against The Pseudodialecticians, pp- 160-195

12 Ibid., p. 57: "At hunc abs quibus auctoribus petunt homines ignari? Non a Cicerone, non a Quintiliano, non etiam a Boetio, hominibus latinis, quibus credi latinis in rebus oported, sed a Petro Hispano..."

${ }^{13}$ Ibid., p. 59: "O miserum Ciceronem, miserum Quintilianum, miserum Boethium, miserum Capellam si uim sermonis latini melius nouit Petrus Hispanus, quam ipsi omnes!" 
modo en que se habla el latín. Lo mismo es cierto de la retórica y la lógica.... pues antes de que la lógica fuera descubierta, esas reglas enseñadas por el lógico ya existran; él se limita a transmitirlas porque el consenso de los hablantes, sea de latín o de griego, así las sanciona". ${ }^{14}$

Pero no es contra la complejidad del discurso lógico escolástico contra lo que Vives propiamente se rebela, toda vez que para él ésta no era sino un atributo del mismo hasta cierto punto necesario. Lo que a él le resulta inadmisible es que semejante complejidad no sea sino una tapadera de la falta de utilidad de las construcciones logicas. Lo que de estas frecuentemente denominadas quisquiliae suicetica ${ }^{15}$ en el fondo molesta a Vives es fundamentalmente su esterilidad o falta de utilidad a la hora de hallar argumentos, ya que para él, como para el resto de los humanistas, la lógica no es una disciplina que tenga interés en sí misma, sino un 'arte de artes', una propedeútica o instrumento para las demás artes.

De esta crítica vivista se desprende con toda claridad que los humanistas vieron en la obra de los lógicos 'modemos' la encarnación de todo cuanto ellos detestaban de la escolástica: el formalismo, la corrupción del latín y en consecuencia de todas las disciplinas basadas en él y, sobre todo, la especulación y la ausencia del menor atisbo de operatividad. Pero la crítica no parecía remedio suficiente para tantos y tan grandes males; la situación parecía demandar una logica nueva, y no tardaron mucho en aparecer voluntarios dispuestos a trabajar en su construcción.

14 Ibid. , pp. 37-39:" Neque enim loquimur ad hunc modum latine, quia grammatica latina ita iubet loqui, quin potius e contrario, ita ita iubet grammatica loqui, quoniam sic latini loquuntur. Res eodem modo se habent in rhetorice et dialectice... Nam antequam ulla dialectica inueniretur, ea erant, ut dialecticus esse docet, quae idcirco docet, quoniam loquentium siue latine siue graece consensus approbat, quapropter praecepta dialectices non minus, quam gramatices atque retorices ad usum loquendi communem aptanda sum."

15 Opera Omnia (ed. G. Mayáns y Síscar, Valencia 1782 ;reed. London, Gregg Press, 1964), VI, p. 196. El término quisquiliae designa lo que cae de los árboles y hay que barrer y suecético es un vocablo que deriva del nombre del calculator Richard Swyneshead (Suiceth). Vives atribuye la autoría de la expresión a Pico della Mirandola. 


\section{La reforma de la lógica}

El primero en compaginar esta actitud crítica que acabamos de analizar con la elaboración de una doctrina altemativa es Lorenzo Valla, quien en 1439 culmina su Repastinatio dialecticae e philosophiae, obra que hoy suele conocerse con el nombre de Dialecticae disputationes y en la que se propone no sólo la tarea de criticar la lógica aristotélicoescolástica, sino también la más positiva de reformar la lógica y reformular sus principios desde una nueva perspectiva. ${ }^{16} \mathrm{El}$ que fuera secretario en la corte de Alfonso el Magnánimo era ya, en el momento de escribir la Dialectica, autor de un influyente trabajo titulado Elengatiae linguae latinae, que respondía al propósito de tratar de establecer el uso correcto de los autores antiguos en ciertos puntos de gramática y estilo, tratando así de restaurar la lengua latina en la pureza que la había distinguido antes de su corrupción en manos de los 'bárbaros'.

Los objetivos perseguidos por Valla en la reforma de la dialéctica emprendida en su Dialectica se podrían sintetizar en los tres siguientes: simplificar la lógica como un todo; reconstruirla sobre el fundamento de un latín claro y correcto, y asimilarla a la retórica, disciplina que constituía el núcleo profesional y el tema predilecto del saber humanista. Una de las tesis centrales de Valla en esta obra es la de que el estudio de la dialéctica ha de ocuparse exclusivamente del lenguaje tal y como se lo emplea en el discurso ordinario. La idea de que la dialéctica no debe apartarse de la senda de las "convenciones de la lengua más frecuentemente usadas" (usitatissima loquendi consuetudine) es la que preside los tres libros de que se compone esta obra, en los que las cuestiones críticas se deciden tomando como base el uso común del lenguaje. Hasta tal punto está Valla convencido de la veracidad de su tesis que cree que el origen de buena parte de los problemas incluidos en el ámbito de la lógica escolástica no es otro que un lenguaje empleado contraviniendo el

${ }^{16}$ De la obra de Valla hay tres versiones, cada una de ellas con un título distinto. Aquí me referiré a ella por el de Dialectica, siguiendo la convención de su editor modemo, $G$. Zippel, en Laurentii Valla Repastinatio dialecticae et philosophiae,(Padua, 1982). Véase la recensión de esta edición hecha por J. Monfasani en Rivista di litteratura italiana 2 (1983), pp. 177-93. 
hábito y la elocuencia, de ahí que los considere irrelevantes desde la nueva perspectiva desde la que él contempla la logica. Este sería a sus ojos el caso, por ejemplo, de los problemas de significado y referencia para cuya solución los lógicos escolásticos elaboraron su famosa teoría de la suppositio.

Pero lo que hace de la Dialectica de Lorenzo Valla una obra seminal de la tradición humanista es el hecho de que en ella el tema de los tópicos o sedes de la argumentación deviene el principal foco de atención, desplazando con ello a la validez formal del sitial de honor que hasta ahora había ocupado en la lógica. Y es que, en la Dialectica de L. Valla, la cuestión de la validez formal de la argumentación deja paso a la de la consideración de cuándo y en qué circunstancias puede decirse que un argumento es 'bueno' teniendo en cuenta su proposito. Valla divide, en efecto, las estrategias que proporcionan 'medium inferens conclusionem' en dos grandes categorias: silogismos y estrategias argumentativas retóricas. Por silogismo entiende Valla, lo mismo que Aristóteles,i.e., cualquier razonamiento deductivamente válido. Aquellos argumentos en los que la conclusión se extrae en base al contenido de las premisas más bien que a la forma de las mismas, como es el caso de las implicaciones analíticas, lo mismo que aquellos en que no hay un nexo lógico entre premisas y conclusión, como es el caso del sorites, son para Valla objeto de atención en tanto que estrategias de incuestionable eficacia en el debate y la discusion. ${ }^{17}$

La Dialectica de Lorenzo Valla contempla ya prácticamente todos los tópicos y temas de discusión que iban a ser característicos del modo humanístico de enfocar la lógica, pero se trata de una obra demasiado densa y oscura como para alcanzar la popularidad y difusión que se requerían para llevar al triunfo al nuevo paradigma. Este papel le

17 Discusiones de la Dialectica de Valla pueden verse en C. Vasoli, op. cit. en nota 1, pp. 28-77; C.I. Camporeale, Lorenzo Valla:Umanesimo e theologia (Florencia, 1972); L. Jardine, "Lorenzo Valla: Academic Skepticism and the New Humanis dialectic", en The Skeptical Tradition, ed. M. F. Burnyeat (Berkeley, 1983), pp 253-286; E. Garin, "Lorenzo Valla e l'umanesimo" y S.I. Camporeale, "Lorenzo Valla <Repastinatio, liber primus> retorica e linguaggio", ambos en $\mathrm{O}$. Besomi y M. Regoliosi eds., Lorenzo Valla e l' umanesimo italiano,(Padua, 1986), pp. 1-17 y 217-239, respectivamente. 
correspondió desempeñarlo más bien a $D e$ inventione dialectica de Rodolfo Agricola, obra que desde el momento de su publicación en 1515 gozará de una gran popularidad, llegando a suplantar como libro de texto a las Summulae Logicales de Pedro Hispano en algunas de las más importantes universidades sobre todo del norte y centro de Europa. ${ }^{18}$

Aunque centroeuropeo, Agricola poseía una sólida formación humanista adquirida en Italia, país al que había acudido a estudiar, atraído por el prestigio de los studia humanitatis de sus universidades. ${ }^{19}$ Esta circunstancia, junto con el renombre que, pese a la brevedad de su vida, llegó a adquirir en prácticamente todas las áreas humanistas del saber, hizo de él una de las principales figuras que sirvieron de puente entre el humanismo italiano y el humanismo del norte. Al menos en el ámbito de la lógica no hay duda alguna de que así fue y de que, con su De inventione Dialectica, desempeño con notable éxito este papel de intermediario entre Italia y paises como Inglaterra y Alemania, paises en los que esta obra alcanzó una notable difusion.

Como el tútulo mismo de este tratado deja ya entrever, lo que Agricola se propone en él no es sino estudiar la lógica de los tópicos, pero dando por sentado que dicho estudio constituye el núcleo mismo de la lógica, pues para él el fin de esta disciplina no es otro que la persuasión (el fidem facere) y el medio, el discurso probable (el probabiliter dicere). También él parte de la consideración de que la dialéctica debe brindar un

${ }^{18}$ La versión canónica de esta obra, que ya circulaba en manuscrito con anterioridad a esta fecha de 1515, es la realizada por su discípulo Alardus (Cologne, 1539), de la que hay dos reimpresiones ( Frankfurt, 1967 y Nieuwkoop, 1967, por la que cito). Sobre la influencia del tratado de Agricola y su implantación como libro de texto en diversas universidades, véase T. Heath, "Logical Grammar, Grammatical Logic and Humanism in three German Universities", Studies in the Renaissance 18 (1971), pp. 9-64, y WJ. Ong, Ramus and Talon Inventory (Cambridge, MA,1958), pp 534-58. En cuanto a las Summulae logicales de Pedro Hispano, sólo conocen a partir de 1528 siete ediciones y todas en Venecia, dato que no deja de desentonar en el marco de la pretendida relación de causa/efecto entre la implantación de los studia humanitatis y el declive de la lógica a la que suele acudirse para explicar éste.

${ }^{19}$ Se sabe que Agricola cursó estudios en las universidades primero de Pavía y luego de Ferrara, en donde estudió con el hijo del célebre Guarino. Para éstos y otros datos relacionados con el tema, véase A. Sottili, "Notizie per il soggiomo in Italia de Rodofo Agricola", en F. Akkerman and A.J.Vanderjagt Rodolphus Agricola Phrisius (E. J. Brill, Leiden, 1988), pp. 79-95. 
conjunto de preceptos útiles o prácticos para la discusión y de que la invención es la parte más importante de la lógica. No es de extrañar pues que, con estos presupuestos, las fuentes de de Agricola sean más o menos las mismas que habían servido de inspiración a Valla, ie., los Topica ciceronianos, la Institutio oratoria de Quintiliano y el De differentiis topicis de Boecio. Por lo demás, de esta preferencia suya por los autores latinos sobre los griegos da fe la división que hace de la lógica en invención y juicio, así como su decisión de concentrar prácticamente todo su interés en la primera de ambas partes.

Los tópicos constituyen, en efecto, el núcleo de $D e$ inventione dialectica. Agricola comienza la discusión de su naturaleza describiendo su utilidad. Teniendo en cuenta las múltiples cosas sujetas a controversia, así como la dificultad para dar con los argumentos necesarios para debatirlas, razona Agricola, "parecen haber hecho algo sumamente útil quienes han diseñado ciertas sedes de argumentos que llamaron 'tópicos', quiados por los cuales, como si de ciertos marcadores se tratara, podemos recorrer con la mente las cosas mismas y ver claramente qué cosas son probables y de uso idoneo en nuestro discurso sobre algo."20

Después de señalar que la familiaridad con los tópicos se adquiere analizando los argumentos esgrimidos por los mejores autores, reconstruyendo las estructuras implícitas en ellos y etiquetando las relaciones tópicas subyacentes, pasa a ofrecer una caracterización de los mismos que es deudora de la ofrecida por Cicerón en Topica II.7. Allí Cicerón había venido a decir que los tópicos son un conjunto de espacios etiquetados, de sedes de los argumentos y él escribe

Estos membretes comunes, en la medida en que contienen todo lo que se puede decir acerca de cualquier materia, también contienen todos los argumentos; por esta razón se les llama tópicos, porque en ellos se hallan dispuestos como si de un refugio o un tesoro se tratara, todos los instrumentos destinados a lograr la persuasión. De donde se

${ }^{20}$ De inventione dialectica, 1539, p. 2. Para una descripción y evaluación del tratamiento que Agricola hace de los tópicos, véase P. Mack, "Rudolph Agricola's Topics", en F. Akkerman, op. cit.pp- 257-270 y M. Cogan, "Rodolphus Agricola and the Semantic revolutions of the history of invention", Rhetorica 2, 1984, pp. 163-194. 
deduce que un tópico no es sino cierto signo común de una cosa a través de cuya dirección se puede hallar todo lo que resulte creible acerca de una determinado asunto. ${ }^{21}$

Cicerón es también la fuente de inspiración de la lista de tópicos que Agricola presenta, lista que si bien supone una mejora tanto de la de aquél como de la de Boecio, no obstante sigue presentando los mismos problemas de heterogeneidad que aquejaban a éstas.

Si los esfuerzos de Valla por derrocar a la lógica del escolasticismo tardío y por sustituirla por una disciplina menos compleja y más estrechamente relacionada con la retórica no tuvieron demasiado eco y su Dialectica no tuvo un verdadero sucesor hasta el De veris principiis, de 1553, de Mario Nizolio, ${ }^{22}$ no ocurrio lo mismo con Agricola, entre cuyos seguidores hay que destacar los nombres de Caesarius, Melanchthon y P. Ramus. Este último en particular habria de ejercer una influencia inmensa, especialmente en el mundo protestante, explicable en parte por la fama que le granjeó su papel de mártir como víctima de la masacre de la noche de San Bartolome. ${ }^{23}$ Esta influencia no fue, empero, desgraciadamente todo lo buena que sería de desear, por cuanto que, a partir de él, y como consecuencia de la esquematización y simplificación a que sometió los logros de sus predecesores con fines fundamentalmente pedagógicos, la tradición humanista comenzo a deslizarse por una pendiente de estudios que fueron gradualmnente apartándose de los temas de las primeras obras, para adentrarse en temas y planteamientos mucho más vulnerables ya a las acusaciones de

${ }^{21}$ Ibíd.., p.9. También L. Vives acude a una comparación para establecer la naturaleza de los tópicos, sólo que él los compara con las etiquetas que ponen farmaceúticos y drogueros en sus tarros a fin de facilitar la localización de lo que buscan. L. Vives, De instrumento probabilitatis, Opera Omnia III, p. 86

22 Ed. de Q. Breen, 2 vols. (Roma, 1956). Nizolio, además de citar a Valla muchas veces a lo largo de esta obra, suscribe la mayoría de sus tesis, entre otras la de la reducción de la lógica a una simple parte de la retórica.

${ }^{23}$ Sobre la obra de P. Ramus y su inmensa repercusión, puede verse el clásico trabajo de W.J. Ong, Ramus, Method and the Decay of Dialogue, Harvard.Univ. Press, 1958. Para una visión que simpatiza más con el autor, véase N. Bruyère, Méthode et dialectique dans l'oeuvre de la Ramée. Renaissance et âge classique, Parin, 1984. 
confusión y falta de rigor lógico que algunos creen achacables a todo el movimiento.

Algunos estudiosos de la logica humanista han argüido recientemente en favor de la idea de que si Agricola y Valla modelaron su obra lógica como lo hicieron fue debido fundamentalmente a que suscribieron las tesis de un escepticismo académico de corte ciceroniano, esto es, de un escepticismo que, si bien niega la posibilidad de alcanzar conocimiento cierto, admite en cambio la probabilidad del mismo. ${ }^{24}$ No me detendré aquí en un tema tan específico como éste, pero lo que sí me gustaría decir es que , para explicar por qué Valla (el caso de Agricola es más complejo) introdujo en su obra el análisis de formas de argumentar como el ejemplo, el entimema o la inducción, cuya fuerza se basa en la probabilidad y la verosimilitud, no hace falta acudir a la hipotesis de su orientación escéptica, sino que basta con reparar en que su concepción de la lógica como una parte de la retórica, que enseguida veremos, requería que dedicara atención a modos retóricos de argumentar.

\section{El puño y la mano abierta}

Pero, aun cuando no parezca haber buenas razones para suponer que ni Valla ni Agricola mantuvieron la concepción escéptica de la Academia, lo que no deja de ser cierto, no obstante, es que la fuente de la que manan muchas de las ideas contenidas tanto en la Dialéctica del primero como en el De inventione dialectica del segundo no es otra que la obra de Cicerón y de Quintiliano. En concreto, la discusión de la invención tópica de la primera de estas obras no es sino una cita textual de $D e$ Institutio oratoria, y, en cuanto a Agricola, si bien abundan las referencias a Aristóteles en su obra, son muchas más también las que hace a Cicerón y Quintiliano. Naturalmente, una cosa es esclarecer la génesis de

24 Véase L. Jardine, "Lorenzo Valla and the intellectual Origins of Humanist dialectic", Journal of the History of Philosophy 15 (1977)pp. 161-63, y el ya citado "Lorenzo Valla" Academic Skepticism", pp272-75. 
unas determinadas ideas y otra bien distinta pensar que éstas se pueden reducir íntegramente a su genesis. El hecho de que se puedan rastrear en los rétores y dialécticos de los siglos XV y XVI intereses y planteamientos presentes en estos autores clásicos no implica en modo alguno que la obra por ellos realizada no sea sino un calco, en lo que a sus contenidos u objetivos se refiere, de la de aquellos. Si ello fuera así, entonces la respuesta a la cuestión de si sus aportaciones tienen o no tienen algún valor para la lógica no ofrecería demasiadas dudas: Dado que la obra ciceroniana dista mucho de ajustarse a los parámetros de lo que normalmente se entiende por una investigación lógica, por ampliamente que queramos entender este concepto, sólo podría ser negativa. Pero, puesto que este no es el caso, lo correcto es proseguir la búsqueda tratando de desentrañar si en el pensamiento de estos dialécticos humanistas concurre o no algún mérito que los haga acreedores a la atención del historiador de la lógica, y para ello, nada mejor que analizar qué pensaban de la naturaleza y objeto de la lógica.

Para la historiografía estándar, según acabamos de ver, la cuestión no ofrece dudas: los análisis que los autores humanistas nos brindan en sus obras no se ajustan a las pautas a que han de conformarse las investigaciones lógicas, sino que se mueven más bien dentro de los cánones propios de alguna otra disciplina como la gramática 0 , sobre todo, la retórica. De acuerdo con esta interpretación, ni la teoŕa de los tópicos desarrollada por Agricola ni las investigaciones sobre la inferencia nodeductiva realizadas por L. Valla entrarían dentro del ámbito de la lógica ni habrían tenido nada que ver con el desarrollo de esta disciplina, sino en todo caso con el de la retórica. Semejante interpretación no concuerda, sin embargo, todo lo bien que sería de desear con el modo de ver las cosas que imperaba a finales de la edad media y comienzos del Renacimiento. En aquella época, los contornos de los estudios de lógica y retórica o -para decirlo con las expresiones acuñadas por Zenón el estoico para señalar las diferencias entre ellas- de las literaturas del puño y la mano abierta, ${ }^{25}$ eran bastante más precisos de lo que hoy se tiende a

${ }^{25}$ Cf. Sexto Empírico, Adv. Math. 2:7; Cicerón, Orator 113 y Quintiliano, Inst. orat., 2:20.7. 
pensar, aunque distintos de los actuales. ${ }^{26}$ Bacon, en cuya obra no es difícil rastrear temas y planteamientos típicos de la tradición humanista, sin que esto quite para que ésta no fuera para él sino una de las tradiciones que habían obstaculizado el avance del saber, escribio a este respecto que la lógica difiere de la retórica "no sólo como el puño de la palma, el uno cerrado, la otra extendida, sino mucho más en lo siguiente: que la lógica trata de la razón exacta y de la verdad, en tanto que la retórica trata de ella tal y como está fijada en los modos y opiniones populares". 27

Pero si los humanistas nunca dejaron de considerar a las disciplinas integrantes del trivium como perfectamente diferenciables desde el punto de vista teórico, por más que defendieran la conveniencia de su unificación a efectos de su enseñanza práctica, lo que sí cambió notablemente con ellos fue la forma de concebirlas y, sobre todo, de interpretar las relaciones entre ellas, especialmente entre lógica y retórica.

Lo primero que tenemos que destacar, a la hora de analizar esta cuestión es que, en contra de lo que normalmente suele suponerse, las posturas de sus principales representantes lejos de ser unánimes, guardan grandes diferencias entre sí, como vamos a ver. Suele entenderse, en efecto, que Agricola escribio su De inventione dialectica bajo la influencia de la Dialectica de Valla, apuntándose así una continuidad en el desarrollo de la lógica y la retorica humanistas que no se corresponde con la realidad, pese a que las coincidencias entre ambas obras no sean tampoco desdeñables. ${ }^{28}$ Son muchos, sin embargo, los aspectos fundamentales en que ambas obras difieren, pero si hubiera que destacar uno, éste sería precisamente el de la interpretación de las relaciones entre

${ }^{26}$ Véase a este respecto, por ejemplo, W.S. Howell, "Poetics, Rhetoric and Logic in Renaissance Criticism", en Classical Influences on European Culture 1500-1700, ed. R.R. Bolgar, Cambridge Univ. Press, 1976, pp. 155-163.

${ }^{27}$ The Works of F. Bacon, ed. de J. Spedding, Boston (1860-65), II, p. 300. Sobre la influencia de la tradición humanista en el pensamiento de Bacon, véase P. Rossi, Francis Bacon: De la magia a la ciencia, Alianza Ed., 1990 y L. Jardine,Discovery and the Art of Discourse, Cambridge Univ. Press, 1974.

${ }^{28}$ Esta continuidad es destacada por prácticamente todos los autores que se han ocupado del tema. Una excepción a esta regla la constituye J. Monfasani, "Lorenzo Valla and Rudolph Agricola", Journal of the History of Philosophy 28 (1990), pp. 181-199. 
lógica y retórica que nos ocupa, pues mientras que Valla redujo lo más posible el estatuto y ámbito de la lógica, Agricola no hizo sino ampliarlo considerablemente a expensas de la retórica.

En el Prefacio al libro segundo de su Dialectica, el primero de los dos que consagra a temas propiamente lógicos, ya que el primero está dedicado por entero cuestiones de índole metafísica, comparando las disciplinas de la dialéctica y la retórica, establece Valla que la lógica es una res brevis prorsus et facilis, y por otra, que no es sino una parte de la disciplina superior y más amplia que es la retórica:

Pues la dialéctica era una cosa enteramente breve y simple, cosa que se desprende de su comparación con la retórica. Pues, qué otra cosa es la dialéctica sino una suerte de confirmación y confutación? Cosas éstas que no son sino partes de la invención, la cual a su vez no es sino una de las cinco partes en que se divide la retórica.' Al dialéctico compete el uso del silogismo'. ¿Cómo?. ¿No emplea lo mismo el orador? De hecho emplea no sólo el silogismo, sino también el entimema y el epiquerema, a lo que podríamos añadir también la inducción. ${ }^{29}$

Una vez establecido que el repertorio argumentativo de la retórica es más amplio y complejo que el de la lógica, prosigue Valla en su intento de diferenciarlas:

El dialéctico emplea el silogismo desnudo, por así decir. El orador lo emplea en cambio vestido de púrpura y provisto y adornado con oro y piedras preciosas, de suerte que si el orador quiere que salgan a la luz, el silogismo pone una amplia gama de preceptos a su disposición. Se podría decir que al dialéctico le corresponde la indigencia. Porque el orador no sólo aspira a enseñar, como el dialéctico, sino también

29 Dialectica, p. 175: "Erat enim dialectica res brevis prorsus et facilis, id quod est comparatione rhetoricae diiudicari potest. Nam quid aliud estdialectica, quam species confirmationis et confutationis?. Hae ipsae sunt partes inventionis, inventio una ex quinque rhetoricae paribus. ?Dialectici est syllogismo uti? Quid, non orator eodem utitur? Immo utitur nec eo solo, verum etiam enthimemate et epiqueiremate, adde etiam inductionem." 
a deleitar y conmover, cosas que algunas veces hacen más por la victoria que la misma prueba. ${ }^{30}$

Repárese en que Valla caracteriza aquí la lógica como uno de los officia oratoris ciceronianos, el de enseñar, haciéndose eco a la vez de la tradición medieval conforme a la cual la logica era ad docendum. Agricola acepta esta idea de que el officium o tarea fundamental de la lógica es la enseñanza, pero va a concebir de un modo muy distinto las relaciones entre ésta y retórica. Para entender su postura en este punto, hay que empezar por reparar en que, para él, uno de las funciones de la enseñanza es la de generar creencia, la de lograr persuadir (fidem facere), y que esto sólo se logra a través de los argumentos probables. Son varios los pasajes en los que Agricola enfatiza que hay muchos temas sobre los que no se puede alcanzar la certeza y que, en tales casos, lo mejor que puede hacerse es argüir convincentemente. Uno de los más claros es el siguiente:

Pues casi todo el mundo habla probabiliter sobre el tema que se ha propuesto enseñar. $Y$ es que no hay un gran surtido de cosas cognoscibles que sean necesarias e indudables, y, de creer en la Academia, ninguna. Nadie niega esto cuando se trata de cosas que pertenecen a la vida y a las normas de conducta. De igual modo, en lo que se refiere al conocimiento de la naturaleza de las cosas, no hay nada que no se pueda defender y debatir desde todos los ángulos con ingenio. De todos estos temas, pues,lo que se discute es lo probable, puesto que lo necesario no se puede. Si lo probable no se pudiera discutir, nadie aprendería ni enseñaría semejantes temas. ${ }^{31}$

${ }^{30}$ Dialectica, pp. 175-176: "Dialecticus utitur 'nudo' (ut sic loquar syllogismo, orator autem 'vestito armatoque, auro et purpura ac gemmis ornato': ut multae sint ei et magnae praeceptorum comparandae divitiae, si videri volet orator, ut dialecticus facih, sed delectare etiam ac movere, quae nonnunquam ad victoriam plus valent qua ipsa probatio."

${ }^{31}$ De inventione dialectica, p. 207: "Omnes enim propemodum probabiliter de eo quod docendum sumpserunt, disserunt. Nam eorum, quae necessaria et indubitata esse posssint, a nobis comprehendi non ita magna est copia, et ( si Academiae credimus) prorsus nulla. Id quod nemo negat, quae ad vitam moresque pertinent; quae item ad rerum naturae notitiam, nihil est qod non sit controversum et magnis ingenits omnes in partes iactatum. 
Ahora bien, a diferencia de lo que ocurría con Valla, para Agricola, la argumentación probable se basa en la teoría de los topoi dialécticos, de la invención tópica, la cual, según vimos arriba, no era para él sino la parte más importante de las dos de que consta la dialéctica. Al asignar pues la argumentación a la invención tópica y al identificar a ésta como la parte fundamental de la dialéctica, Agricola reducirá drásticamente el papel tradicionalmente asignado a la retórica, circunscribiendo su cometido únicamente al tema de la omamentación del discurso (elocutionis ornatus), a la disposición de las palabras en orden a conquistar la sensibilidadd del auditorio. El ámbito de la dialéctica se verá por contra notablemente ampliado, ya que, aunque circunscrita en teoría a la probabilitas dictionis, pasará a incorporar buena parte de los temas tradicionalmente tratados dentro de la retorica.

Es, pues, innegable que, al identificar prácticamente la lógica con la invención tópica, Agricola retorizó la lógica, la sometió a las demandas y valores de la retórica, pero no lo es menos que, al hacerlo, devolvió la lógica a su antigua posición de dux directrixque omnium artium de la que había sido destronada por obra de los primeros humanistas. ${ }^{32}$ La lógica deviene de nuevo un ars artium, pero ni qué decir tiene que en un sentido muy distinto del que tenía entre los escolásticos de la edad media, ${ }^{33}$ pues si bien parece que se mantiene el consenso respecto a que la tarea de la lógica es ocuparse de los 'buenos argumentos', lo que ahora va a entenderse por semejante expresión dista mucho de ser idéntico, toda vez que 'buen argumento' ya no se toma como sinónimo de argumento formalmente válido y que la validez formal ya no se considera la única vía de acceso a semejante categoría. Parece, sin embargo, que esta nueva concepción humanista de la lógica no se aparta tanto de la mantenida por Aristóteles, el cual muy bien pudiera ocurrir que en este punto estuviera

De his ergo omnibus probabilia utcunque disseruntur, quoniam necessaria non posssunt. Nam sine probabilia quidem possent, nemo vel disceret ea vel doceret." véase también p.193.

${ }^{32}$ De inventione dialectica, p. 180.

${ }^{33}$ Cf. M. Cogan, "Rodolphus Agricola and the Semantic Revolution of the History of Invention", Rhetorica 2 (1984). 
siendo más fielmente interpretado por los humanistas, pese a su declarado antiaristotelismo, que por quienes se reclamaban seguidores suyos. ${ }^{34}$

Como se recordará, el propósito de Aristóteles en los Tópicos no es otro que el de presentarnos una práctica dialéctica que resulte útil en las discusiones, esto es, el de proveer de un arte de argumentar, según declara el autor al comienzo de los mismos. Ahora bien, Aristóteles es plenamente consciente de que, si la dialéctica supone argumentar desde opiniones plausibles -y es precisamente el carácter plausible de las premisas, y no su forma logica, lo que en su opinión hace dialéctico a un argumento- entonces, a la hora de evaluar un argumento dialéctico, no habrá más remedio que tomar en consideración las opiniones y creencias de los oyentes o del auditorio, ya que, a diferencia de lo que ocurre con el argumento demostrativo, que vale para cualquiera, el argumento dialéctico es siempre función de aquellos en quienes se pretende influir con él, es decir, del marco discursivo en el que se halla inmerso. Pero el hecho de reparar en que la estimación de la corrección del argumento dialéctico ha de hacerse atendiendo al marco discursivo en el que éste se desenvuelve no llevo, sin embargo, a Aristóteles a perder de vista que una cosa es la persuasividad de un argumento y otra muy distinta su validez y su 'cogencia' o valor de prueba, pues, aunque no resulta fácil determinar con precisión qué relación es la que él crefa que mediaba entre dialéctica y retórica, dada la equivocidad del término antistrophos del que se valió para caracterizarla, ${ }^{35}$ lo que sí parece claro es que no

\footnotetext{
34 Una de las bases sobre las que se cimentó el humanismo fue la recuperación de la lengua griega, que después de un olvido casi total durante la edad media vivirá una etapa de auténtico esplendor con los humanistas. Por iniciativa suya no sólo se crean cáiedras de griego en las universidades más importantes, sino que se inicia una labor de recuperación de los clásicos griegos a través de la edición de sus obras y de nuevas traducciones. Como consecuencia de ello, la interpretación medieval de Aristóteles, en este como en otros campos, fue dando paso paulatinamente a una nueva interpretación, de suerte que el estudio de Aristóteles en el Renacimiento distó mucho de ser una mera continuación del aristotelismo medieval. Cf. los distintos estudios de C. B. Schmitt recogidos en Aristotle and the Renaissance, Cambridge Univ. Press, 1983.

${ }^{35}$ Retórica I 1354 a 1 Antistrophos ha solido traducirse como 'el análogo 'o 'la contrapartida'. Sobre este tema de las relaciones entre Retórica y Dialéctica en Aristóteles, véase el reciente artículo de Jacques Brunchwig, "Rhetorique et dialectique, Rhetorique et Topiques", en Aristotle's Rhetoric, ed. de D.J. Furley and A. Nehamas( Princeton Univ. Press, 1994), pp. 57-96.
} 
se trata en modo alguno de una relación de identidad. Dicho de otro modo, parece que no cabe la menor duda de que lo que Aristóteles está haciendo en los Tópicos es proponer un modo de acercamiento al estudio de la argumentación que si bien es más amplio que el preconizado en los Primeros Analíticos, toda vez que por argumento parece que se entiende aquí el intercambio entre dos personas que arguyen -en el sentido de que discuten- una cierta cuestion, no se confunde, aunque a veces es inevitable que se solape, con el propio de la retórica.

Algo más o menos similar me parece a mi que ocurre en el caso que nos ocupa. Los humanistas no es que no confirieran al estudio de la lógica un ámbito propio y netamente distinto del de la retórica, sino que, al hacer tanto hincapié en la utilidad que este estudio había de tener, al resaltar tanto el carácter de arte que para ellos tenía la lógica, se vieron abocados a introducir en él algunas cuestiones que parecen no guardar relación directa con el tema de la inferencia válida, i. e., con lo que hoy se considera el tema de la investigación lógica. Sin embargo, antes de condenar este enfoque al limbo de la retórica, hay que reparar en que a él es achacable también, por ejemplo, el análisis de estrategias argumentativas que, si bien no tenfan cabida dentro de la teoria deductiva entonces conocida, i.e., la silogística, el propio Aristóteles trató al final de sus $A n$. Pr., o la discusión de inferencias cuya validez depende del significado de los términos en ellas involucrados más que de las propiedades formales de premisas y conclusión, discusión que naturalmente no tiene cabida en un estudio de la inferencia a través de sistemas formales, pero se hace inevitable cuando dicho estudio se realiza a través del lenguaje ordinario, el único medio del que entonces se disponía para expresar los desarrollos lógicos. Precisamente fue la falta de un lenguaje formal lo que hizo que los escolásticos se vieran abocados muchas veces a forzar el lenguaje común y a introducir barbarismos en él con objeto de poder expresar sus soluciones a sofisticados problemas formales. Pero esto no fueron capaces de verlo los humanistas que interpretaron tales 'aberraciones' lingüísticas como indicios de barbarie y de mal uso del latín por parte de tales autores. Es más, creo que es en su preocupación por tratar de enseñar la logica de un modo simple y efectivo, en un lenguaje lo más simplificado posible, más bien que en la famosa 'retorización', en donde reside una de 
las claves explicativas de por qué , bajo sus auspicios, se fue desvirtuando el contenido de la lógica. El hecho de que semejante preocupación no sea detectable sólo en los humanistas, sino también, por ejemplo, en los jesuitas que produjeron los cursus artium en universidades como las de Coimbra o Alcalá, no viene sino a abundar aún más en la idea de que la relación entre los humanistas y el deterioro de la logica es bastante más compleja de lo que hasta ahora se nos ha estado tratando de hacer creer. 